\title{
Are there differences in clinical and laboratory parameters between children and adults with American visceral leishmaniasis?
}

\author{
Arlene J.M. Caldas ${ }^{\mathrm{a}, \mathrm{b}, *}$, Jackson Costa ${ }^{\mathrm{a}}$, Dorlene Aquino ${ }^{\mathrm{a}, \mathrm{b}}$, \\ Antônio Augusto M. Silva ${ }^{\text {d, }}$, Manoel Barral-Netto ${ }^{\text {a,c }}$, Aldina Barral ${ }^{\text {a,c }}$ \\ a Centro de Pesquisas Gonçalo Moniz, Fundação Oswaldo Cruz (FIOCRUZ), Salvador, BA, Brazil \\ b Departamento de Enfermagem, Universidade Federal do Maranhão, UFMA, São Luís, MA, Brazil \\ ${ }^{\mathrm{c}}$ Faculdade de Medicina da Bahia, Universidade Federal da Bahia, UFBA, Salvador, BA, Brazil \\ d Departamento de Saúde Pública, Universidade Federal do Maranhão, UFMA, São Luís, MA, Brazil
}

Received 8 March 2005; received in revised form 30 August 2005; accepted 27 September 2005

Available online 18 January 2006

\begin{abstract}
A prospective study on 23 patients with American visceral leishmaniasis (VL), comparing clinical and laboratory parameters of 14 children (mean age of $3.85 \pm 3.39$ years) to nine adults (27.4 \pm 10.90 years) was performed in São Luís, Maranhão, Brazil, between August 2000 and July 2002. Data were collected at entrance (day 0), end of treatment, as well as 120 and 210 days after treatment using a protocol chart containing patient identification, clinical and laboratory data. $N$-Methylglucamine antimonate administered at the dose of $20 \mathrm{mg} / \mathrm{Sb}^{5+} / \mathrm{kg} /$ day for 20-30 days was successfully used in all patients. Patients were followed for 1 year after treatment, and no relapses were observed. A prolonged duration of the disease, lymphadenopathy and bleeding predominated in adult patients, while hepatomegaly and skin-mucosal pallor were more frequent in children. Disease was longer and more severe in adults than in children. Although both groups exhibited a trend toward normalization of hematological and biochemical parameters, more children returned sooner to normal values than adults. Difference in clinical or laboratory parameters between children and adults did not indicate the need for different clinical or therapeutic approaches.
\end{abstract}

(C) 2005 Published by Elsevier B.V.

Keywords: American visceral leishmaniasis; Children; Adults; Delayed-type hypersensitivity; Lymphoproliferative response

Visceral leishmaniasis (VL) represents an important public health problem in the world. In the Americas it is commonly caused by Leishmania (Leishmania) chagasi, with Brazil accounting for more than $90 \%$ of the human cases occurring in the continent (OPAS, 1997; Brasil

\footnotetext{
* Corresponding author at: Laboratório de Imunoparasitologia (LIP) do Centro de Pesquisas Gonçalo Moniz-Fundação Oswaldo Cruz/FIOCRUZ-Bahia, Rua Valdemar Falcão, 121 (Brotas), Salvador/Bahia, CEP 40 295-001, Brazil.

E-mail addresses: ajmc@elo.com.br (A.J.M. Caldas), jcosta@cpqgm.fiocruz.br (J. Costa).
}

et al., 2004). In some Andean countries (Venezuela, Colombia, Ecuador, Peru and Bolivia) VL is rare. In Venezuela VL incidence was 0.2 cases per 100,000 inhabitants in 1998 (Davies et al., 2000). VL affects individuals of different ages, but a predominance in adults has been observed in southeast Asian countries (Ashford et al., 1992).

In Brazil, the disease preferentially affects children younger than 10 years and $75 \%$ of cases occur in those younger than 5 years (Araújo Sobrinho et al., 1999; Brasil et al., 2004). According to the Brazilian Ministry of Health, from 1984 to 2002 there were 48,455 
VL cases. Mean number of cases per year was 3500 and lethality was $6.0 \%$. Incidence rate up to 20.4 cases per 100,000 inhabitants has been observed in some places. Nearly $66 \%$ of the cases occurred in four Brazilian states (Bahia, Ceará, Piauí and Maranhão). In 2003 the prevalence in Maranhão state was 15 cases per 100,000 and reduced to 10.3 cases per 100,000 in 2004 (Werneck et al., 2002; Brasil et al., 2004).

Differences in clinical presentation and severity have been reported between VL in children and adults (Hohenschild and Feldmeier, 1995). These studies however compare cases from different regions and alterations arising from the infectivity and antigenicity of the Leishmania parasite and/or from diverse immune capacity and natural or acquired resistance due to genetic differences of the host may play a role in the reported differences.

In view of the importance of VL in Brazil and the differences that might exist between different age groups, the aim of the present study was to analyze clinical and laboratory profile of children and adults with the disease.

\section{Materials and methods}

A prospective study was conducted on 23 patients with VL, including 10 patients seen at hospitals belonging to the Brazilian public health system (SUS), and 13 patients seen at the Infectious and Parasitic Diseases outpatient clinic at the Federal University of Maranhão (UFMA), São Luís, MA, Brazil. The study was performed between August 2000 and July 2002. The study was approved by the Research Ethics Committee of "Hospital Universitário Presidente Dutra", and all patients or responsible persons signed a free informed consent form.

Included in the study were patients living in the municipalities of São Luís Island (São Luís, São José de Ribamar, Paço do Lumiar and Raposa), who had not started VL treatment, and who agreed to participate in the study. Excluded were patients who did not adhere to regular follow-up defined as attendance of the scheduled return visits.

Diagnosis was confirmed by identification of amastigote forms of Leishmania sp. in Giemsa-stained smears of bone marrow aspirates.

All patients received $N$-methylglucamine antimonate (Glucantime ${ }^{\circledR}$ ) as the drug of first choice at the dose of $20 \mathrm{mg} / \mathrm{Sb}^{5+} / \mathrm{kg} /$ day (maximum dose of $810 \mathrm{mg} / \mathrm{day}$ ), intravenously, over a period of 20-30 days (Brasil et al., 2004). Two adult patients complained of myalgia at the beginning of treatment but discontinuation of the drug was not required. One pregnant patient was treated with amphotericin B at the dose of $1 \mathrm{mg} / \mathrm{kg} /$ day for
14 days (Thakur et al., 1999; Caldas, 2004). Patients with marked anemia (3+/4+ hypopigmented and/or hemoglobin $\leq 5 \mathrm{~g} / \mathrm{dl}$ ), hemorrhagic phenomena, severe diarrhea, impaired general and/or nutritional status, and associated infection or disease were treated with $20 \mathrm{mg} / \mathrm{Sb}^{5+} / \mathrm{kg} /$ day for 30 days in hospitals and the remainder in outpatient clinics. Patients in the initial phase of the disease were treated in outpatient facilities with the same dosage for 20 days.

Data were collected using a standard protocol chart containing the following information: identification, presence of animals in the dwelling and neighborhood, clinical complaints, physical exam, and the results of laboratory tests performed before (day 0 ) and after therapy (30 days). All patients underwent clinical-evolutive follow-up every 10 days during treatment, monthly up to 3 months after treatment, and then every 3 months until completing 12 months. Clinical assessment consisted of recording the symptoms reported by the patient or responsible person and complete clinical examination including measurement of spleen and liver size and weight. All patients underwent anti-HIV antibody test to investigate possible co-infection. Only one patient was positive and was excluded from the study.

Data were analyzed with the EPI-INFO version $6.04 \mathrm{~b}$ (CDC, Atlanta, USA) and GraphPad Prism version 2.0 (GraphPad Software Inc., 1995) programs. The mean and standard deviation were calculated for the variables age and time of residence. The absolute frequency was considered for the following epidemiological variables: living in an endemic area, presence of dogs, presence of foxes and sand flies, sick animals in the neighborhood, and a family history of kala-azar. Clinical variables such as fever, splenomegaly, hepatomegaly, skinmucosal pallor, cough, diarrhea, adenomegaly, bleeding, pneumonia, and intestinal worms are reported as absolute frequency before treatment. These variables were compared between children and adults by the chi-square test, and Fisher's test was used when the expected frequency was lower than five.

Percent variation was calculated for some variables with different normality parameters per age group: liver and spleen size, weight, and hematological and biochemical data. Percent variation was calculated as the final value minus the initial value divided by the initial value and the result is reported as proportion, which, multiplied by 100 , gives the percentage. The initial value corresponds to data obtained before treatment (day 0) and the final value corresponds to data obtained at the end of treatment (30 days). Negative percent variation indicates that the final value was lower than the initial 
value, and positive variation indicates the opposite. The unpaired Student's $t$-test was used to compare these variables between children and adults.

For comparison of the laboratory tests before and after treatment in each group, the paired Student's $t$-test was used when the results showed a normal distribution and the nonparametric Wilcoxon test for paired observations was used when the distribution was not normal. Normality was determined with the Shapiro-Wilk test. A $P$-value $\leq 0.05$ was considered to be statistically significant.

\section{Results}

Twenty-three patients with a classical picture of kalaazar were analyzed prospectively, including $14(61 \%)$ children aged $1-9$ years (mean of $3.82 \pm 2.39$ ), $78 \%$ of them younger than 5 years, and $9(39 \%)$ adults (16-51 years, mean of $27.44 \pm 10.90$ ).
The male/female ratio was $1: 1$ in children and 1.2:1 in adults. With respect to occupation, the most frequent activities among adults were maid/housewife (33\%), grocer $(23 \%)$, guard, student, electrician, and without occupation (11\% each). No significant difference in epidemiological variables was observed between children and adults (Table 1).

The duration of the disease from the onset of signs and symptoms to diagnosis was shorter in children $(7.14 \pm 8.58$ weeks $)$ than in adults $(14.22 \pm 9.62$ weeks $)$ (Table 2).

Reduction in spleen size was on average of $60 \%$ in children and $36 \%$ in adults whereas liver size reduction was $54 \%$ in children and $49 \%$ in the adult group at the end of treatment. It should be noted that all children had hepatosplenomegaly, and albeit reduced hepatosplenomegaly was observed in $60 \%$ of the patients who concluded treatment. Of these, $5 \%$ presented a palpable spleen ( $\pm 3 \mathrm{~cm}$ from the left costal margin) at 120

Table 1

Demographic and epidemiological characteristics of the patients with American visceral leishmaniasis (São Luís, MA, 2002)

\begin{tabular}{llll}
\hline Variable & Children $(n=14)$ & Adults $(n=9)$ & $P$-value \\
\hline Age (years) & $3.82 \pm 2.39^{\mathrm{a}}$ & $27.44 \pm 10.90^{\mathrm{a}}$ & $1.2: 1$ \\
Male:female & $1: 1$ & $4.00 \pm 15.00^{\mathrm{a}}$ & 0.147 \\
Time of residence (years) & $2.00 \pm 3.50^{\mathrm{a}}$ & $9(100 \%)$ & 0.423 \\
Living in an endemic area & $13(93 \%)$ & $9(100 \%)$ & 0.423 \\
Presence of dogs & $13(93 \%)$ & $9(55 \%)$ & 0.543 \\
Presence of foxes & $6(49 \%)$ & $6(67 \%)$ & 0.423 \\
Presence of sand flies & $13(93 \%)$ & $3(33 \%)$ & 0.909 \\
Sick animals in the neighborhood & $9(64 \%)$ & & 0.655 \\
Family history of VL & $6(43 \%)$ & &
\end{tabular}

a Data are reported as mean \pm standard deviation.

Table 2

Clinical characteristics of the children and adults with American visceral leishmaniasis (São Luís, MA, 2002)

\begin{tabular}{|c|c|c|c|}
\hline Variable & Children $(n=14)$ & Adults $(n=9)$ & $P$-value \\
\hline Duration of the disease (weeks) & $7.14 \pm 8.58^{\mathrm{a}}$ & $14.22 \pm 9.62^{\mathrm{a}}$ & 0.039 \\
\hline Duration of hospitalization (days) & $16.33 \pm 3.14^{\mathrm{a}}$ & $21.25 \pm 6.29^{\mathrm{a}}$ & 0.257 \\
\hline Percent variation in liver size & $-0.362 \pm 0.214^{\mathrm{a}}$ & $-0.496 \pm 0.291^{\mathrm{a}}$ & 0.393 \\
\hline Percent variation in spleen size & $-0.600 \pm 0.291^{\mathrm{a}}$ & $-0.540 \pm 0.321^{\mathrm{a}}$ & 0.659 \\
\hline Percent variation in weight & $0.080 \pm 0.116^{\mathrm{a}}$ & $0.045 \pm 0.073^{\mathrm{a}}$ & 0.607 \\
\hline Fever & $14(100 \%)$ & $7(78 \%)$ & 0.071 \\
\hline Splenomegaly & $14(100 \%)$ & $8(89 \%)$ & 0.212 \\
\hline Hepatomegaly & $14(100 \%)$ & $6(67 \%)$ & 0.023 \\
\hline Skin-mucosal pallor & $13(93 \%)$ & $5(55.5 \%)$ & 0.038 \\
\hline Cough & $8(57 \%)$ & $4(44 \%)$ & 0.560 \\
\hline Diarrhea & $7(50 \%)$ & $6(67 \%)$ & 0.441 \\
\hline Adenomegaly & $2(22 \%)$ & $6(67 \%)$ & 0.017 \\
\hline Bleeding & 0 & $4(44 \%)$ & 0.014 \\
\hline Pneumonia & $5(36 \%)$ & $1(11 \%)$ & 0.208 \\
\hline Intestinal parasitosis & $6(43 \%)$ & $2(22 \%)$ & 0.290 \\
\hline
\end{tabular}

Percent variation was calculated subtracting the final value from the initial value and then dividing the result by the initial value.

${ }^{a}$ Data are reported as mean \pm standard deviation. 
Table 3

Hematological and biochemical data obtained for children and adults with American visceral leishmaniasis before (day 0$)$ and at the end of treatment (30 days) (São Luís, MA, 2002)

\begin{tabular}{|c|c|c|c|c|c|c|}
\hline \multirow[t]{2}{*}{ Parameter } & \multicolumn{3}{|l|}{ Children } & \multicolumn{3}{|l|}{ Adults } \\
\hline & Day 0 & 30 days & $P$-value & Day 0 & 30 days & $P$-value \\
\hline Erythrocytes $(\times 1000 / \mathrm{mm})$ & $2.98 \pm 0.65$ & $4.0 \pm 0.60$ & $<0.001$ & $2.97 \pm 0.50$ & $3.67 \pm 0.70$ & 0.043 \\
\hline Hemoglobin $(\mathrm{g} / \mathrm{dl})$ & $7.18 \pm 1.77$ & $9.38 \pm 1.93$ & $<0.001$ & $8.0 \pm 0.87$ & $9.44 \pm 1.85$ & 0.056 \\
\hline Hematocrit (\%) & $22.7 \pm 5.18$ & $29.7 \pm 4.84$ & $<0.001$ & $24.56 \pm 2.93$ & $32.26 \pm 6.19$ & 0.013 \\
\hline Leukocytes $\left(\mathrm{mm}^{3}\right)$ & $6371 \pm 5886$ & $13410 \pm 6715$ & 0.010 & $2448 \pm 775$ & $4527 \pm 1506$ & 0.008 \\
\hline Eosinophils $\left(\mathrm{mm}^{3}\right)$ & $164 \pm 320$ & $1641 \pm 2076$ & 0.014 & $61.2 \pm 60.5$ & $394.8 \pm 406.4$ & 0.044 \\
\hline Segmented cells $\left(\mathrm{mm}^{3}\right)$ & $1864 \pm 1706$ & $5262 \pm 2992$ & 0.005 & $1523 \pm 1199$ & $1965 \pm 943.9$ & 0.115 \\
\hline Lymphocytes $\left(\mathrm{mm}^{3}\right)$ & $4109 \pm 4453$ & $4817 \pm 2509$ & 0.411 & $1022 \pm 372.5$ & $1661 \pm 800.8$ & 0.064 \\
\hline Platelets $\left(\mathrm{mm}^{3}\right)$ & $148200 \pm 80.4$ & $382900 \pm 111.9$ & 0.002 & $109900 \pm 47.42$ & $217000 \pm 93.2$ & 0.007 \\
\hline Urea (mg/dl) & $16.85 \pm 7.22$ & $13.5 \pm 5.82$ & 0.081 & $17.11 \pm 3.41$ & $19.56 \pm 6.02$ & 0.234 \\
\hline Creatinine $(\mathrm{mg} / \mathrm{dl})$ & $0.46 \pm 0.13$ & $0.43 \pm 0.12$ & 0.456 & $1.21 \pm 1.24$ & $1.27 \pm 1.41$ & 0.802 \\
\hline Globulin (U/ml) & $3.26 \pm 1.11$ & $1.93 \pm 0.68$ & 0.006 & $3.57 \pm 0.86$ & $1.80 \pm 0.26$ & 0.002 \\
\hline Albumin (U/ml) & $2.49 \pm 0.91$ & $3.45 \pm 0.83$ & 0.023 & $2.13 \pm 0.67$ & $3.63 \pm 0.61$ & $<0.001$ \\
\hline Glycemia (mg/dl) & $79.86 \pm 4.94$ & $79.57 \pm 4.94$ & 0.611 & $78.44 \pm 4.6$ & $77.44 \pm 2.74$ & 0.505 \\
\hline $\mathrm{AST}^{\mathrm{a}}(\mathrm{U} / \mathrm{l})$ & $76.50 \pm 39.68$ & $60.67 \pm 28.1$ & 0.088 & $68.56 \pm 38.16$ & $44.44 \pm 25.1$ & 0.065 \\
\hline $\mathrm{ALT}^{\mathrm{b}}(\mathrm{U} / \mathrm{l})$ & $51.51 \pm 47.22$ & $31.43 \pm 12.1$ & 0.090 & $46.89 \pm 22.22$ & $30.67 \pm 15.63$ & 0.050 \\
\hline $\operatorname{ESR}^{\mathrm{c}}(\mathrm{mm})$ & $95.29 \pm 35.68$ & $76.29 \pm 25.53$ & 0.125 & $114.2 \pm 24.45$ & $111.4 \pm 29.59$ & 0.606 \\
\hline
\end{tabular}

Data are reported as mean \pm standard deviation.

a Aspartate aminotransferase.

b Alanine aminotransferase.

${ }^{c}$ Erythrocyte sedimentation rate.

days after treatment, which was no longer palpable by the sixth month of follow-up.

With respect to weight, a mean increase of $8 \%$ was observed in the children's group and of $5 \%$ in the adult group at the end of treatment. However, weight gain was more marked at 120 days, with a mean of $141 \%$ in children and of $128 \%$ in adults. No significant difference in the duration of hospitalization, percent variation in spleen and liver size or percent variation in weight was observed between children and adults (Table 2).

Regarding clinical aspects, hepatomegaly and skinmucosal pallor were more frequent in the children's group, while lymphadenopathy and bleeding (discrete melena and otorrhagia) predominated among adults. No significant difference was observed between the two groups regarding the frequency of fever, splenomegaly, cough, diarrhea, pneumonia or intestinal parasitosis (Table 2). Most patients (90\%) were without fever at the end of the first week of treatment.

With respect to hematological and biochemical findings, only $22 \%$ of the adult patients achieved normal standards at the end of treatment, and in the other patients these values returned to normal 120 days after treatment (Table 3). Comparison of the two groups revealed no significant difference in terms of hematological or biochemical variables (Table 4).
No relapses were observed in either adults or children during the 1-year follow-up period after treatment.

\section{Discussion}

The present work was conducted in order to identify potential clinical or laboratory differences in VL presentation between children and adults, with emphasis on differences which may have had an impact on diagnostic or therapeutic approaches. We took advantage of the occurrence of VL in these two age groups in the same geographic region, minimizing differences in genetic background of the human population, or diversity in parasite behavior as well as reducing differences in clinical care observed in distinct regions or countries. There were few differences in clinical and laboratory parameters between children and adults with VL. These differences did not indicate a need for different clinical or therapeutic management in these sub-groups.

Environmental changes have been associated with the epidemiological profile of kala-azar, with an increasing number of reports of outbreaks in urban and periurban areas, suggesting an adaptation of the vector and its ecosystem to these areas. In the present study, no differences in several variables representative of environmental exposure were observed between children or adults. The presence of both domestic (dog, Canis famil- 
Table 4

Difference in the percent variation of hematological and biochemical parameters between children and adults with American visceral leishmaniasis (São Luís, MA, 2002)

\begin{tabular}{|c|c|c|c|}
\hline Parameter & Children & Adults & $P$-value \\
\hline Erythrocytes $(\times 1000 / \mathrm{mm})$ & $0.221 \pm 0.855$ & $0.200 \pm 0.260$ & 0.943 \\
\hline Hemoglobin (g/dl) & $0.357 \pm 0.355$ & $0.200 \pm 0.224$ & 0.250 \\
\hline Hematocrit (\%) & $0.364 \pm 0.361$ & $0.344 \pm 0.240$ & 0.825 \\
\hline Leukocytes $\left(\mathrm{mm}^{3}\right)$ & $2.81 \pm 4.118$ & $-1.178 \pm 1.129$ & 0.263 \\
\hline Eosinophils $\left(\mathrm{mm}^{3}\right)$ & $8.950 \pm 39.59$ & $7.878 \pm 8.00$ & 0.196 \\
\hline Segmented cells $\left(\mathrm{mm}^{3}\right)$ & $4.176 \pm 7.313$ & $0.800 \pm 1.163$ & 0.187 \\
\hline Lymphocytes $\left(\mathrm{mm}^{3}\right)$ & $0.300 \pm 0.95$ & $0.757 \pm 1.03$ & 0.432 \\
\hline Platelets $\left(\mathrm{mm}^{3}\right)$ & $2.086 \pm 2.371$ & $0.867 \pm 1.052$ & 0.163 \\
\hline Urea $(\mathrm{mg} / \mathrm{dl})$ & $0.229 \pm 0.182$ & $0.300 \pm 0.206$ & 0.402 \\
\hline Creatinine (mg/dl) & $0.186 \pm 0.192$ & $0.389 \pm 0.379$ & 0.102 \\
\hline Globulin (U/ml) & $-0.343 \pm 0.277$ & $-0.378 \pm 0.327$ & 0.786 \\
\hline Albumin (U/ml) & $0.529 \pm 0.521$ & $0.789 \pm 0.446$ & 0.231 \\
\hline Glycemia (mg/dl) & $0.043 \pm 0.051$ & $0.033 \pm 0.050$ & 0.665 \\
\hline $\operatorname{AST}^{\mathrm{a}}(\mathrm{U} / \mathrm{l})$ & $0.324 \pm 0.176$ & $0.400 \pm 0.269$ & 0.405 \\
\hline $\operatorname{ALT}^{\mathrm{b}}(\mathrm{U} / \mathrm{l})$ & $0.586 \pm 0.789$ & $0.411 \pm 0.247$ & 0.537 \\
\hline $\operatorname{ESR}^{\mathrm{c}}(\mathrm{mm})$ & $0.534 \pm 0.674$ & $0.111 \pm 0.093$ & 0.077 \\
\hline
\end{tabular}

Data are reported as mean \pm standard deviation. Percent variation was calculated subtracting the final value from the initial value and then dividing the result by the initial value.

a Aspartate aminotransferase.

b Alanine aminotransferase.

${ }^{\mathrm{c}}$ Erythrocyte sedimentation rate.

iares) and wild reservoirs of the parasite (fox, P. vetulus or $C$. thous), as well as of the vector ( $L$. longipalpis) was similar in both groups. Together with the precarious living conditions, these aspects render the environment prone to transmission of the disease (Lacerda, 1994; Caldas et al., 2001,2002).

The duration of the disease from the onset of signs and symptoms to diagnosis was longer in adults, a finding probably due to the difficulty sometimes encountered by local health personnel in identifying the disease in adults since the disease is more frequent in children. Hohenschild and Feldmeier (1995), in Germany, also found differences in mean duration of VL, where the disease lasted 1 month in children and 2.5 months in adults. Sud et al. (2004) in Asia found mean duration of the disease to be about $3.8 \pm 3.4$ months, and Collin et al. (2004) in Africa, observed the duration to be 2 months among adults. Singh et al. (1999), in Nepal, observed mean duration in children to be lower than 6 months.

In Brazil mean duration of the disease among adults was longer than in other countries (14.2 \pm 9.6 weeks), maybe because of delayed diagnosis. Earlier diagnosis of VL among adults would help curb mortality rate and decrease patients showing up in the advanced form of the disease.

The most marked findings in children with VL were hepatomegaly and skin-mucosal pallor. Children aged less than 3 years old normally present a palpable liver measuring approximately $3 \mathrm{~cm}$ (Carneiro-Sampaio and Grumach, 1992) what is probably responsible for the reported hepatomegaly in children with VL. Children are generally more susceptible to other infectious diseases, a fact explaining the presence of pneumonia in 5 $(36 \%)$ children of the present series and supported by the relatively higher frequency of neutropenia and lymphocytosis in this group since neutrophils are cells of the first-line defense against bacteria.

Another sign predominating in children and confirmed by the hematological findings was skin-mucosal pallor. This result demonstrates the importance of complementary exams in the evaluation of patients with kala-azar. Cough was observed in $57 \%$ of children, generally being dry and persistent at the onset of the disease, remaining unchanged and disappearing at the end of treatment, characteristics suggestive of interstitial pneumonitis attributed to VL which sometimes is confused with other diseases, especially pneumonia (Andrade, 1959; Duarte et al., 1989).

Diarrhea was observed in more than half of the patients studied, but no specific cause could be identified in some of them. This symptom disappeared during treatment, a finding suggesting Leishmania-induced enteritis (Zijlstra et al., 1992). Adenomegaly is common in African and Asian kala-azar (Zijlstra et al., 1992), but is mild in American VL. However, less pronounced adenomegaly was observed in six adults and two children 
of the present series. Al-Jurayyan et al. (1992), studying 63 cases of VL, found small lymph nodes in the axillary, cervical and inguinal region of 14 (22\%) patients. In contrast, Zijlstra et al. (1992) did not detect splenomegaly in $9 \%$ of patients with VL ( $2 \%$ children and $7 \%$ adults).

The most common clinical caractheristics of VL both among children and adults in Brazil were not so much different from what has been observed in other continents (Mittal et al., 1989; Singh et al., 1999; Sarker et al., 2003). In American, European, Asian and African kala-azar the classic triad (fever, hepatosplenomegaly and skin-mucosal pallor) predominated.

Weight loss with various degrees of malnutrition was observed mainly in children, but the difference between children and adults was not statistically significant. This was also observed by Zijlstra et al. (1992) in Africa. VL may have contributed to aggravate malnutrition since most of the patients recovered $23 \%$ of their lost body weight by the end of the treatment.

Among the hematological alterations identified in the present sample, significant anemia was observed in most patients. This was also found by Rahim et al. (1998), Sarker et al. (2003) in Asia, and Collin et al. (2004) in Africa. Hemoglobin concentration in children suffering from VL was lower than in adults as was also observed by Zijlstra et al. (1992). This may only reflect normal differences in hemoglobin concentration between children and adults rather than meaningful clinical differences.

The reduction or absence of eosinophils was demonstrated in the two groups before treatment, but children showed eosinophilia at the end of treatment, indicating a good prognosis (Prata, 1957; Singh et al., 1999; Brasil et al., 2004). However, it was necessary to take into account co-morbidity due to the presence of other parasitoses, a fact that can increase the percentage of eosinophils to over 20\% (Prata, 1957; Rodrigues da Silva, 1957; Campos Jr., 1995; Caldas, 2004), as observed in some children in the present series.

Total number of white blood cells varied from 600 to $10,800 / \mathrm{mm}^{3}\left(\right.$ mean $\left.=3572 / \mathrm{mm}^{3}\right)$. Mean platelet count was $88,000 / \mathrm{mm}^{3}$. The majority of the patients also exhibited neutropenia and lymphopenia. The same finding has also been observed in Asia by Rahim et al. (1998) and Singh et al. (1999) among children and Sarker et al. (2003) among adults.

All patients showed an effective response to treatment with $\mathrm{Sb}^{5+}$, with progressive improvement in the presentation of the disease characterized by the disappearance of fever in the first week of treatment and subsequent improvement in general status, weight gain and regression of anemia, leukopenia and thrombocytopenia. At the end of the first trimester of follow-up, normalization of the hematological parameters and disappearance of hepatosplenomegaly were observed. Based on clinical and laboratory data during follow-up no treatment failure or relapse was observed in the patients studied.

In conclusions there were no significant differences in clinical or laboratory parameters between children and adults that would indicate different clinical or therapeutic management.

\section{Acknowledgements}

We thank Dr. Ana Cristina Saldanha and Dr. Mônica Elinor Alves Gama for support in the endemic area.

This work was supported by a grant from the Fundação de Amparo à Pesquisa do Estado da Bahia (FAPESB) and by grant AI 30639 from the National Institutes of Health. A.B. is a senior investigator from the Brazilian Research National Council (CNPq) and J.C. has a research fellowship from FAPESB.

\section{References}

Al-Jurayyan, N.A.M., Al Ayed, I.H., Al-Nasser, M.N.S., Al-Mugeiren, M.M.A., Boohene, A.G., Al Herbish, A.S., 1992. Visceral leishmaniasis in infancy and childhood epidemiology and clinicopathological study of 63 cases in Al-baha Province, Saudi Arabia. J. Trop. Pediatr. 38, 12-16.

Andrade, Z.A., 1959. Pneumonia intersticial no kala-azar. Hospital 71, 55.

Araújo Sobrinho, J., Rodrigues, M.L.C., Gonzaga, A.A.D., Celino, A.C.B.L., 1999. Aspectos epidemiológicos, laboratoriais e terapêuticos da leishmaniose visceral no hospital Universitário Alcides Carneiro-PB. Rev. IMIP 13, 13-16.

Ashford, R.W., Desjeux, P., Raadt, P., 1992. Estimation of population at risk of infection and number of cases of leishmaniasis. Parasitol. Today 8, 104.

Brasil, 2004. Fundação Nacional de Saúde, Secretaria de Vigilância em Saúde. Departamento de Vigilância Epidemiológica. Manual de vigilância e controle da leishmaniose visceral. Ministério da Saúde, Brasilia, Brasil.

Caldas, A.J.M., Costa, J.M.L., Silva, A.A.M., Vinhas, V., Barral, A., 2002. Risk factors associated with asymptomatic by Leishmania chagasi in northeast Brazil. Trans. R. Soc. Trop. Med. Hyg. 95, $1-8$.

Caldas, A.J.M., Silva, D.R.C., Pereira, C.C.R., Nunes, P.M., Silva, B.P., Silva, A.A.M., Barral, A., Costa, J.M.L., 2001. Infecção por Leishmania (Leishmania) chagasi em crianças de uma área endêmica de leishmaniose visceral americana na Ilha de São Luís, MA, Brasil. Rev. Bras. Med. Trop. 34, 445-451.

Caldas, A.J.M., 2004. Marcadores precoces de eficácia terapêutica na leishmaniose visceral humana em crianças e adultos. Doctoral thesis, Universidade Federal da Bahia. Faculdade de Medicina, Centro de Pesquisas Gonçalo Moniz, Salvador, BA, Brazil.

Campos Jr., D.C., 1995. Características clínico-epidemiológicas do calazar na criança. Estudo de 75 casos. J. Pediatr. 71, 261-265.

Carneiro-Sampaio, M.M.S., Grumach, A.S., 1992. Alergia e imunologia em pediatria. Sarvier, 257 pp. 
Collin, S., Davidson, R., Retmeijer, K., Keus, K., Malaku, Y., Kipngetich, S., Davies, C., 2004. Conflict and kala-azar: determinants of adverse outcomes of kala-azar among patients in Southern Sudan. Clin. Infect. Dis. 38, 612-619.

Davies, C.R., Reithinger, R., Campbell-Lendrum, D., Feliciangeli, D., Borges, R., Rodriguez, N., 2000. The epidemiology and control of leishmaniasis in Andean countries. Cad. Saúde Pública 16, $1-42$.

Duarte, M.I., Matta, V., Corbett, C.E.P., Laurenti, M., Chebabo, R., Goto, H., 1989. Interstitial pneumonitis in human visceral leishmaniasis. Trans. R. Soc. Trop. Med. Hyg. 83, 73-76.

Hohenschild, S., Feldmeier, H., 1995. Imported kala-azar in children and adults comparison of medical history, clinical and diagnostic findings. J. Trop. Pediatr. 41, 378-379.

Lacerda, M., 1994. The Brazilian leishmaniasis control program. Mem. Inst. Osw. Cruz 89, 484-495.

Mittal, V., Bhatia, R., Sehgal, S., 1989. Clinocoepidemiological profile of kala azar patients in Delhi. J. Commun. Dis. 21, 255261.

Organização Pan-Americana de Saúde (OPAS), 1997. Manual de controle da leishamniose viseral. Organização Mundial de Saúde, Geneba.

Prata, A., 1957. Quadro clínico e laboratorial do calazar. Arq. Bras. Med. Naval 65, 12-260.

Rahim, F., Rehman, F., Ahmad, S., Zada, B., 1998. Visceral leishmaniasis in District Dir, NWFP. J. Pak. Med. Assoc. 48, 161-162.
Rodrigues da Silva, J., 1957. Leishmaniose visceral (calazar). Rio de Janeiro. Thesis, Faculdade Nacional de Medicina, Rio de Janeiro. Serviço Nacional de Educação Sanitária, 498 pp.

Sarker, C.B., Chowdhury, K.S., Siddiqui, N.I., Jamal, M.F., Rahman, S., Momen, A., Dhar, D.K., Alam, K.S., 2003. Clinical profile of kala-azar in adults: as seen in Mymensingh Medical College Hospital, Mymensingh, Bangladesh. Mymensingh Med. J. 12, 41-44.

Singh, K., Singh, R., Parija, S.C., Faridi, M.M., Bhatta, N., 1999. Clinical and laboratory study of kal-azar in children in Nepal. J. Trop. Pediatr. 45, 95-97.

Sud, A., Varma, N., Marwaha, Rh., Patel, F.M., trehan, A., singh, S., Varma, S., 2004. Visceral leishmaniasis in a non-endemic area of India. Trop. Doct. 34, 247-249.

Thakur, C.P., singh, S.M., Hassan, R.K., Narin, S., Kumar, A., 1999. Amphotericin B deoxycholate treatment of visceral leishmniasis with newer modes of administration and precautions: a study of 938 cases. Trans. R. Soc. Trop. Med. Hyg. 93, 319-328.

Werneck, G.L., Rodrigues Junior, L., Santos, M.V., Araújo, I.B., Moura, L.S., lima, S.S., Gomes, R.B.B., Maguire, J.H., Costa, C.H.N., 2002. The burden of Leishmania chagasi antigens recognized in cured visceral leishmaniasis and asymptomatic infection. Acta Trop. 83, 13-18.

Zijlstra, E.E., Siddig, A.L.I., Ali, M., El-Hassan, A.M., El-Toum, I.A., Satti, M., Ghalib, H.W., 1992. Clinical aspects of kala-azar in children from the Sudan: a comparison with the disease in adults. J. Trop. Pediatr. 38, 17-21. 